over 1000 pilgrims of different nationalities, among whom were a few cases of cholera. These pilgrims underwent their quarantine at Camaran, and no further cases, as far as I know, have been reported among them. Discussions on the subject in the past have usually been very unsatisfactory and the conclusions very indefinite. The serious fact remains that cholera epidemics among the pilgrims annually collected at Mecca are of very frequent occurrence and are a standing menace to Egypt and Europe. Four times within the last twelve years the disease might have been introduced by the pilgrims into Egypt or Europe, or both, and the experience of France and Spain has shown how easily it may become endemic. The endeavours of the Quarantine Board have fortunately been successful in stamping out the disease before the pilgrims reached Egypt. The doings of the Board have been very severely criticised in England-often rightly, but oftener undeservedly and without connaissance de cause. Its actions in the future will be very much modified by the decisions of the Conference of Venice-a conference entirely due to the action of some of the members of the Board who took the initiative and drew up a programme for their government with a view to settle on a more rational basis and smooth over the ever-irritating question of Suez Canal quarantine.

Alexandria.

\section{PITYRIASIS RUBRA IN A CASE OF DIABETES.}

\section{BY HERBERT H. HORDEN, M.D. LOND.}

Pityriasis RUBRa, also sometimes called exfoliative dermatitis, is a rare disease and, unlike most skin affections, involves the whole surface of the body. The occurrence of this disease in a diabetic subject, so far as I can ascertain, has not been previously recorded, and therefore I have thought it sufficiently interesting to publish the case in some detail. That eczema is a complication of diabetes is well known, and since some authorities are inclined to regard pityriasis rubra as a form of eczema the association of the two diseases in the present case is of interest.

The patient, a woman aged seventy, consulted me on May 27th, 1892, on account of great irritation and burning of the lower part of the body. She stated that she had been troubled with it for two or three weeks, but, hoping that it would pass off, she had not taken any pains in treating it, having only applied some ointment, which had given her no relief. On inquiring into her past history I was told by her that she had always led a very active life and had been very healthy and temperate. There was no history of gout or rheumatism in her family. She had noticed during the last few months that she had been growing languid and exhausted, particularly after any exertion, and that though her appetite was very good and at times even ravenous she was losing flesh. Thirst was not complained of, but on closer inquiry it was discovered that she consumed a considerable quantity of water during the night. She complained of her rest being disturbed at night by her having to get up so many times to micturate. She also complained of constipation. On examination the patient appeared to be Wealthy, though the skin of the face was somewhat flabby and loose, giving one the idea that there had been loss of fesh. It was, however, quite free from any eruption. The eyes were carefully examined, but, with the exception of a well-marked arcus senilis, there was nothing abnormal to be detected in the lenses or discs. The skin on the chest and extremities was distinctly dry and somewhat harsh, but with this exception it was normal; on the abdomen, however, extending from midway between the umbilicus and pubic symphysis, there was a well-defined area of a deep-red colour covered with an innumerable number of very thin papery scales overlapping each other, very easily detached, and sxtending to the vulva. The area was very dry to the touch, and there were no crusts to be seen. She complained of great heat and burning over this part, as well as of much irritation. Physical examination of the chest and abdomen revealed nothing abnormal. She was told to measure the quantity of urine passed during the next twenty-four hours and to send a specimen of it to be tested. The amount was determined to be nine pints. It was of a light amber colour and quite clear, and there were no deposits. The specific gravity was 1034. There was no albumen, but Fehling's solution showed the presence of sugar, which was subsequently estimated to be eight grains to the ounce. The patient was not seen for a fortnight, when I was summoned to her house. The rash had then spread over the whole of the abdomen and the lower part of the chest, as well as over the whole of the back, buttocks, and upper parts of the thighs. She said that it was spreading daily and always did so from the edges. Around the edges were seen numerous well-defined red patches, which were slightly raised above the general surface of the skin. Those nearest to the edges were covered with scales and appeared to run into each other, while those more distant had but few scales. In this manner the rash appeared to spread all over the body, including the face and scalp, and also the soles of the feet and palms of the hands. The ears and eyelids were likewise affected. The scales on the face were much smaller than those of the body. The rash took six weeks to envelop the whole body. When the scalp was attacked the hair rapidly fell out, so that the patient became quite bald. When the scales were removed from any part the subjacent skin was intensely red and very tender to the touch. They had everywhere the same character, being, namely, very thin, papery, and imbricated, and not glued together. They appeared to form again almost as soon as removed. The nails of the hands and feet were not affected. The quantity of scales which were shed daily was estimated to be about a pint and a half. The patient complained of great tingling, burning, and heat all over the body, and also of her eyes smarting so much that sbe was obliged to wear a shade to protect them from the light, which seemed to irritate them.

The treatment of the case consisted in keeping the patient confined to one room raised to a moderate temperature, and, during the acute stage, in bed. All draughts were excluded as far as possible, as it was found that she felt the cold keenly. She was put on a strictly diabetic diet, and no wines or malt liquors were permitted, but claret was allowed. Pills containing codeia were ordered three times a day. The local treatment consisted of a calamine liniment composed of calamine, oxide of zinc, and olive oil. This was constantly applied all over the body by soaking lint in the liniment and then winding it round the patient's body and limbs, while it was also dabbed over her face. Each morning the scales were brushed off with a soft brush. The local treatment was faithfully carried out by a daughter, who acted as nurse to the case, and who also looked after the diet. After the rash had become general arsenic was given internally and its effect watched for fourteen days, but as it certainly did no good it was discontinued and the dose of codeia increased. After four months' treatment, by which time the sugar had quite disappeared, the skin affection began to improve, particularly on the legs, but the burning and tingling of the skin increased. For this a mixture containing gelsemium and quinine was prescribed, which gave marked relief. The parts to become well last were the front of the chest and under the breasts. The hair, which had completely fallen off the scalp, has now grown thickly and sbundantly. The skin at the present time is quite free from any eruption, but feels finer and thinner than before the illness, and the patient is very susceptible to cold and perspires freely. The whole duration of the affection was about nine months. Water-lare, Brixton.

\section{HIGH TENSION, HEADACHE, AND ALBUMINURIA.}

\section{By H. WILLOUGHBY GARDNER, M.D., L.R.C.P. LOND.,} M.R.C.S. ENG.

A MAN aged thirty-five came to me on April 6th, 1891, complaining of severe recurrent headaches from which he had suffered since boyhood. He stated that his father had suffered from similar headaches all his life, and that at the age of fifty-eight he began to suffer from softening of the brain, became more and more irritable and strange, and eventually died from that disease at the age of sixty-five. He said he was very like his father in temperament and physique, and his fear was that he himself would eventually suffer from similar brain disease, and that too at an earlier age. Twelve years ago he had suffered from "brain fever," which lasted for six weeks, and during which he had been delirious and unconscious. He recovered completely. He had had no other illness. There was no history of syphilis. His mother, 